\title{
Políticas Públicas de Memória: O Programa Pontos de Memória no Contexto Sul-Rio-Grandense
}

\author{
Políticas Públicas de Memoria: El Programa Pontos de Memória en Rio \\ Grande do Sul
}
Public Policys about Memory: The Pontos de Memória Program in Rio Grande do Sul

\begin{abstract}
Resumo
O presente estudo busca realizar uma análise do Programa Pontos de Memória, do Instituto Brasileiro de Museus. Analisando o Programa, observa-se a iniciativa de preservar a memória de determinados grupos sociais considerados excluídos da representação de museus ditos tradicionais, através da implementação de espaços de memória ou ações sociomuseológicas, que narrem suas histórias a partir do suporte de patrimônios locais. A análise parte de questionamentos iniciais: quais são as memórias e as identidades que o Programa seleciona para narrar, através de quais ferramentas ocorre a divulgação e sobretudo a apropriação deste patrimônio por parte da comunidade? Para analisar as causas e os efeitos desta política pública, o trabalho observará e discutirá o alcance e a influência que esses espaços exercem nas comunidades, as ações desenvolvidas e a longevidade desses espaços ou ações no contexto sul-rio-grandense.
\end{abstract}

Palavras-Chave: Comunidade, Museologia Social, Políticas Públicas Culturais, Programa Pontos de Memória, Rio Grande do Sul

\section{Resumen}

El presente estudio busca realizar un análisis del Programa Puntos de Memoria, del Instituto Brasileiro de Museus (Brasileño de Museos). Analizando el Programa, se observa la iniciativa de preservar a la memoria de determinados grupos sociales considerados excluidos de la representación de museos dichos como tradicionales; a través de la implementación de espacios de memoria sociomuseológicos o acciones, que narren sus historias a partir del soporte de patrimonios locales. El análisis parte de dos cuestionamientos iniciales: ¿cuáles son las memorias y las identidades que el Programa selecciona para narrar?, ¿a través de cuales herramientas ocurre la divulgación y sobre todo la apropiación de este patrimonio por parte de la comunidad? Para analizar las causas y los efectos de esta política pública, el trabajo observará y discutirá el alcance y la influencia que esos espacios o acciones ejercen en las comunidades, las acciones desarrolladas y la longevidad de esos espacios en el contexto de Rio Grande do Sul.

Palabras clave: Comunidad, Museología Social, Políticas Públicas Culturales, Programa Puntos de Memoria, Rio Grande do Sul

\begin{abstract}
This study aims to accomplish an analysis of Pontos de Memória Program, from the Instituto Brasileiro de Museus (Brazilian Institute of Museums). Analyzing the program, we can observe the initiative to preserve the memory of certain social groups considered excluded from representation of traditional museums, by implementing memory spaces or actions sociomuseological, which narrate stories from the local heritage

\footnotetext{
${ }^{1}$ Bacharela em Museologia; mestranda em Memória Social e Patrimônio Cultural; Universidade Federal de Pelotas - UFPEL; Pelotas, Rio Grande do Sul, Brasil; mariana.boujadi@gmail.com.
} 

e-ISSN 2016/Atual: 2525-7870 | e-ISSN 2015/2016: 2447-018X

support. The analysis begins with this initial questions: what are the memories and identities that the program selects to narrate; by which tools is the dissemination and especially the appropriation of this heritage made for the community? To analyze the causes and effects of public policy, this paper will observe and discuss the scope and influence that these spaces have on communities and the actions taken and the longevity of these spaces or actions in the Rio Grande do Sul context.

Key-words: Community, Sociomuseology, Public Policys for Culture, Programa Pontos de Memória, Rio Grande do Sul

\section{O Programa Pontos de Memória}

O estudo em questão aborda uma análise crítica da política de memória denominada Programa Pontos de Memória, para compreender como estes espaços se articulam com as comunidades nas quais estão inseridos e como o discurso oficial apresenta estas articulações.

Implantado em 2009, segundo o site do Instituto Brasileiro de Museus, o Programa Pontos de Memória do Ministério da Cultura e Instituto Brasileiro de Museus em parceria com Projeto de Cooperação Técnica Internacional da Organização dos Estados IberoAmericanos para a Educação, a Ciência e a Cultura, tem como objetivo apoiar e incentivar ações de reconhecimento e valorização da memória social através de uma metodologia dialógica e participativa, trabalhando a memória de forma viva de acordo com interesses do grupo comunitário, possui um conceito que se aproxima muito daqueles relacionados à museologia social. O PPM em sua fase inicial (2009-2011) experienciou a inserção do Programa em doze comunidades, escolhidas não por acaso, mas por fazerem parte de um outro programa social do Governo Federal em parceria com o Ministério da Justiça, o Programa Nacional de Segurança Pública com Cidadania. Foram estas as comunidades Comunidade de Terra Firme, em Belém- PA; Comunidade do Taquaril, Belo Horizonte- MG; Comunidade da Estrutural, Brasília- DF; Comunidade do Sítio Cercado- Curitiba- PR; Comunidade Grande Bom Jardim, Fortaleza- CE; Comunidade do Jacintinho, Maceió- AL; Comunidade da Lomba do Pinheiro, Porto Alegre- RS; Comunidade do Coque, Recife- PE; Comunidades do Pavão-Pavãozinho-Cantagalo, Rio de Janeiro- RJ; Comunidade da Brasilândia, São Paulo- SP; Comunidade do Beiru, Salvador- BA e Comunidade do São Pedro, Vitória- ES. Atualmente existem 137 Pontos de Memória espalhados pelos pais, selecionados através de editais disponibilizados pelo IBRAM.

Dentre os princípios estruturantes da própria metodologia descrita um deles é o protagonismo das comunidades, mas como será que este protagonismo ocorre de fato dentro destes espaços ou ações que são os Pontos de Memória?

Compreendeu-se, devido ao grande número de Pontos de Memória no país, a necessidade de realizar um recorte espaço-temporal, que permita, ao mesmo tempo, aliar a 
aproximação da resposta que se almeja com a exequibilidade da pesquisa. Dessa forma, optou-se por abranger, neste recorte, os Pontos de Memória localizados no estado do Rio Grande do Sul implantados entre os anos de 2009, data de criação do Programa, e 2015.

Neste sentido, buscando responder a essas questões no recorte espaço-temporal estabelecido, propõe-se um amplo estudo de todos os Pontos de Memória do Rio Grande do Sul, mais antigos ou mais recentes, onde se possa realizar um demonstrativo da efetividade dessa política pública no estado de forma mais profunda e abrangente.

Assim é necessário observar o que seria um política cultural de memória e como ela funcionaria no contexto do Programa.

Segundo a Unesco no documento Cultural policy: A preliminary study, política cultural é um conjunto de princípios operacionais, práticas administrativas e orçamentárias e os procedimentos que fornecem uma base para a ação cultural do Estado que busca atender a determinadas necessidades culturais utilizando-se de todos os recursos materiais ou imateriais disponíveis. (UNESCO, 1969, p. 4)

Para Vinyes uma política pública é a combinação de três elementos: um objetivo, um programa e um instrumento. No caso de políticas culturais de memória, o objeto consistiria no patrimônio. O programa seriam as atuações destinadas a preservar, estimular e transmitir esse patrimônio. E o instrumento seria a ação do Estado para garantir o desenvolvimento do programa. (2009, sp)

Ou seja, no caso do Programa Pontos de Memória, o objetivo seria a iniciativa de preservar uma memória de determinados grupos sociais, a partir de patrimônios locais, considerados excluídos da representação de museus ditos tradicionais. O programa seria seu modus operandi de atuação, ou seja, através da implementação de espaços de memória sociomuseológicos que narrem as histórias destas comunidades consideradas excluídas. E o instrumento seria o Estado brasileiro, representado pelo MinC, e a OEI.

O patrimônio é um ponto chave para o Programa Pontos de Memória e para a política que ele desenvolve. Pois, comumente, é através do patrimônio que se produz uma identidade materializada, como um relicário da memória transformado em um relicário de uma noção de passado, onde diversos grupos se dedicam a encontrar e/ou fabricar traços, relíquias, vestígios, arquivos, de forma a permiti-los se narrar. (CANDAU, 2011, p. 158-9).

Espaços de memória, como museus, são catalizadores dessa questão, havendo a noção de preservação e consagração de memórias e identidades, tentando projetá-las como a memória de todos, mas "o patrimônio apresentado como comum a todos não é senão o patrimônio de alguns" (CANDAU, 2009, p.54) porque a ideia de uma identidade que 
possibilite o pertencimento de todos é, em si, questionável dadas as diferentes percepções de identidade e de patrimônio, há, então, nesses espaços, aquelas identidades que são legitimadas em detrimento de outras, deixando de representar determinados grupos de memória (RODRIGUES, SERRES, 2013, p. 46), pode-se considerar que isto ocorre, em geral, em qualquer tipo de política de memória.

O Programa Pontos de Memória, trata-se de uma política cultural de preservação da memória de grupos sociais, e, observa-se, ao discutir políticas públicas de memória e esquecimento, que "a Sociologia da memória é fundamental, pois possibilita articular as diferentes manifestações da memória e compreender as tensões entre as narrativas do passado e um sistema de inter-relações sociais" (FERREIRA, 2009, p.105). Para Le Goff "O estudo da memória social é um dos modos fundamentais de abordar os problemas do tempo e da história, relativamente aos quais a memória está ora em retraimento, ora em transbordamento" (1984, p. 13). Pois não é unicamente o indivíduo que tem controle sobre resgate do passado, "a memória é constituída por indivíduos em interação, por grupos sociais, sendo as lembranças individuais resultado desse processo" (ARAUJO; SANTOS, 2007, p. 97). Temse, assim, que é “crença no compartilhamento de lembranças origina essa memória compartilhada, o que estaria na base da função política da memória ou daquilo que se denomina hoje como “políticas de memória”. (FERREIRA, 2009, p. 105)

A tentativa de, através de políticas de memória, estabelecer a memória de um grupo pode gerar discussões e disputas internas a comunidade, pois compreende-se "que é possível o confronto entre a memória individual e a memória dos outros, isso mostra que a memória e a identidade são valores disputados em conflitos sociais e intergrupais, e particularmente em conflitos que opõem grupos políticos diversos" (Pollack, 1992, p.5). Esses confrontos e estas disputas estão presentes nos Pontos de Memória.

Um exemplo destes confrontos relaciona-se há existência de Pontos de Memória em determinadas comunidades que não são de conhecimento sequer de pessoas engajadas politicamente com estas localidades.

Estudos anteriores (SILVA, 2015) abarcaram questões referentes aos doze Pontos de Memória iniciais, onde observou-se, o caso do Ponto de Memória da Estrutural, em Brasília, onde apesar de haver um projeto de extensão universitário da Universidade de Brasília, em depoimento, moradores do bairro há décadas, engajados com organizações relacionadas a eles, jamais ouviram falar nem do espaço de memória, nem da ação universitária. 
Compreende-se, contudo, que muitas vezes aquele discurso oficial do Projeto de ser inclusivo e contar com uma metodologia que conte com participação ativa de membros da comunidade, pode se tornar apenas um exercício acadêmico.

Brulon Soares e Scheiner afirmam a respeito de museus comunitários um pensamento que pode abarcar outras tipologias de espaços sociomuseais, como são todos os Pontos de Memória, quando dizem que, na maioria dos casos estes espaços passam por pelo menos uma das seguintes situações: a institucionalização, a compartimentação ou se autoconsomem (2009, p.3). Ao se institucionalizarem assemelham-se mais com os museus tradicionais. Isso ocorre, quando por exemplo, lideranças assumem o papel norteador da ação em nome da comunidade ou quando a participação da comunidade é mínima em detrimento a projetos planejados por instituições de pesquisa (como museus maiores ou Universidades).

A compartimentação ocorre quando há um discurso destoante da ação, na teoria o museu se diz de uma maneira e age diferente do seu discurso, o espaço afirma-se inclusivo e aberto a participação da comunidade, mas possui todas as ações museológicas organizadas por um grupo restrito de agentes patrimoniais, muitas vezes externos a comunidade. Ao se autoconsumir, o museu esgota suas propostas em votações e assembleias e paralisam a ação, fagocitando o interesse pelo patrimônio através do projeto político.

\section{Análise dessa Política Pública}

Para analisar o Programa Pontos de Memória no recorte espaço-temporal estabelecido, e alcançar os objetivos estabelecidos neste estudo, utiliza-se uma metodologia interdisciplinar, contemplando estudos conceituais e bibliográficos, análise de discurso, trabalho de campo e história oral.

Esta metodologia é fundamental para realizar uma verdadeira analise de políticas públicas sobre o Programa Pontos de Memória, para compreender sua eficácia. Através dela é possível responder às seguintes questões: quem ganha o quê, por quê e que diferença faz socialmente. (SOUZA apud LASWELL, 2006, p. 35)

Sendo esta uma pesquisa em desenvolvimento e em um estágio inicial no mestrado do Programa de Pós-graduação em Memória Social e Patrimônio Cultural os resultados ainda se apresentam de forma superficial.

Assim, houve um levantamento de todos os Pontos de Memória localizados no estado do Rio Grande do Sul. São eles os Trajetos da Memória em Osório; a Casa da Cultura do Litoral Boizinho da Praia em Cidreira; Ponto de Memória TV OVO em Santa Maria; O projeto Construindo Espaços Museais Populares em São Leopoldo; o Projeto Fontes de 
pesquisa \& debates para a igualdade étnico-racial no Brasil em Porto Alegre e o Museu Comunitário da Lomba do Pinheiro, também em Porto Alegre.

Este levantamento inicial possibilitou uma observação mais aprofundada destes espaços. A partir de diversas mídias como: jornais, revistas, sites, blogs, e dos próprios editais do Programa Pontos de Memória, que alguns destes espaços possuem forte relações com Universidades Federais, Escolas Públicas, Bibliotecas e Arquivos. Pretende-se a continuidade deste estudo e compreender até que ponto estas relações influenciam na participação da comunidade nestes espaços bem como na apropriação, por parte dela, do patrimônio local. Também deseja-se compreender, como comentado, as articulações entre os discursos oficiais e as realidades nos espaços de memória.

\section{Conclusões}

Por se tratar de um estudo em desenvolvimento, não há, ainda, resultados prontos para serem apresentados, porém, observa-se um potencial no projeto do Programa Pontos de Memória, bem como nos casos estudados e analisados anteriormente, a incorrerem nas situações expostas por Brulon e Scheiner (2009). Este potencial também permeia as questões referentes no que diz respeito as memórias que são selecionadas para compor uma representação identitária de determinada comunidade através dos Pontos de Memória, que apesar de buscarem um distanciamento dos museus ditos tradicionais, talvez acabem por aproximarem-se demasiadamente deles.

Tem-se, então, a ideia de que há nesta política de memória um caráter de “dever de memória" (Ferreira, 2011, p. 108), apoiadas na tentativa da inclusão de grupos considerados historicamente excluídos, podendo ou não responder às reivindicações memoriais dos grupos que almeja representar.

\section{Referências}

BRASIL, Ministério da Cultura, IBRAM. Disponível em <http://www.museus.gov.br> acesso em 10 fev. 2015.

BRASIL, Ministério da Cultura. IBRAM. Edital do Programa Pontos de Memória de 2014. 2014, disponível em <http://www.museus.gov.br/wpcontent/uploads/2014/10/Edital_PremioPontosdeMemoria_2014.pdf> acesso em 10 jul.2014

BRULON SOARES, B. C. ; SCHEINER, T. C. M. . A ascensão dos museus comunitários e os patrimônios comuns : um ensaio sobre a casa.. In: X Encontro Nacional da Associação Nacional de Pesquisa em Ciência da Informação, 2009, João Pessoa. E-book do Encontro 
Nacional da Associação Nacional de Pesquisa em Ciência da Informação. João Pessoa: Idéia, v. 10, 2009.

CANDAU, Joël. Antropología de la memória. Trad. Paula Mahler. Buenos Aires: Nueva Visión, 2006.

CANDAU, Joël. Bases antropológicas e expressões mundanas da busca patrimonial: memória, tradição e identidade. Memória em Rede, Pelotas, v. 1, ano 1, jan./jul. 2009.

CANDAU, Joël. Memória e identidade. Trad. Maria Letícia Ferreira. São Paulo: Contexto, 2011

FERREIRA, M.L.M. Políticas da memória e políticas do esquecimento. Aurora. V.10. 2011

LERSH, T. M ; OCAMPO, M. O Conceito de Museu Comunitário : História Vivida ou Memória para transformar a história. In Conferencia Nacional de la Asociación Nacional de Artes y Cultura Latinas, Kansas, Missouri, 6-10, out. 2004.

MOUTINHO, M. Definição evolutiva de sociomuseologia. Cadernos de Sociomuseologia, Lisboa, V. 28, n 28, p. 1-6, 2007.]

OLIVEIRA, WENDY. [Correspondência por mensagem] 13 de jan. 2015, Brasília [para] SILVA, MARIANA. Pelotas. Ponto de Memória da Estrutural em Brasília.

POLLAK, Michael. Memória e Identidade Social. Trad. Monique Auguras. Ed. Dora Rocha. Estudos Históricos, Rio de Janeiro vol. 5, n. 10, p. 200-212, 1992.

PONTO DE MEMÓRIA ESTRUTURAL. (Brasília, DF). Disponível em < http://memoriaestrutural.blogspot.com.br/ > acesso em 16 fev. 2015.

RODRIGUES, A. R; SERRES, J. P. Museu: memória e esquecimento do individual ao coletivo. Mouseion, v. 14, p. 37-48, abr. 2013.

SILVA, M.B.M. Políticas Públicas de Incentivo à Cultura e os Museus Comunitários: O Caso do Programa Pontos de Memória. Pelotas: UFPel, 2015. Monografia

SOUSA, C. Políticas Públicas: uma revisão da literatura. Sociologias. Porto Alegre, ano 8, $\mathrm{n}^{\circ}$ 16, jul/dez 2006, p. 20-45

UNESCO. Cultural policy: a preliminary study. UNESCO: Paris, 1969

VARINE, Hugues de. “O Museu Comunitário É Herético? Inquietações Amplamente Compartilhadas.” Interactions Online. 2005. Trad. OMP. Disponível em < http://www.abremc.com.br/artigos1.asp?id=9 > acesso em 17 abr. 2014

VINYES, R. La memoria como política pública. El País. Espanha. sp. 6 de jan. de 2009. Disponível em <http://elpais.com/diario/2009/01/07/opinion/1231282813_850215.html> acesso em 10 de fev. 2016 